\title{
The Morphology of Abu Dhabi's Superblocks: A Modernist Vision
}

\author{
By Apostolos Kyriazis* \\ Ahmed Almehairi ${ }^{\dagger}$ \\ Ibrahim Al Serit
}

Abu Dhabi's transition from a fishing village to a contemporary capital city in less than 50 years is more than remarkable. Its rapid growth, fueled by oil revenues and combined with a real estate frenzy and an overmanaged public space is reflected into the main characteristic of Abu Dhabi's urban morphology: the Superblocks. This paper is part of a wider Research program regarding the Urban Regeneration initiative for the Superblocks as it derives from Abu Dhabi's Strategic "2030 Plan". It examines their origins and evolution that swings between raw pragmatism and specific modernist influences. It also argues in favor of an alternative regeneration approach that could be based on this modernist heritage and furthermore apply bottom-up participatory procedures to reinforce the city's shallow collective memory. To the support of that argument, a case study of a specific Superblock will be presented. The analysis of its morphological properties, their drawbacks and opportunities may forge a new regeneration pathway. One that rises from the individual plot to the urban scale, actively engages the end users and leads to more flexible/less formal urban action. A potential success may function as a pilot for other Superblocks to follow and also as a regeneration paradigm for other GCC cities to activate their social, historic and cultural capital.

\section{Introduction}

Despite the fact that Abu Dhabi's urban history spans only fifty years, it seems that the high growth rate of the city (directly comparable to the one of a human being) piggybacked by oil revenues, leaves little room for the creation of a historic layering, a palimpsest, that would build upon, protect and take advantage of the properties of this sequence that is vital to a city's success as a social capacitor. The so-called collective memory and eventually the creation of an urban identity, in parallel with a national one are forged within such environments and in return they operate as an added value to the direction of time.

In the absence of a pre-oil core, Abu Dhabi's buildings are set to live in a "laisser faire" mode guided only by real estate market rules and be replaced in pre-arranged time periods regardless of their aesthetic value and their overall contribution to the context. In an oddly similar way, the citizens themselves are also considered highly expendable. The expatriate communities of the city that

\footnotetext{
* Assistant Professor, Abu Dhabi University, UAE.

${ }^{\dagger}$ Architect ADU \& MSc Student, British University of Dubai, UAE.

${ }^{\ddagger}$ Architect ADU, National Consultant Office, UAE.
} 
make the vast majority of the population mix arrive, work and live under the knowledge of temporality, as this being the philosophy of the visa-providing system in the UAE (sponsor-based).

Abu Dhabi's horizontal sprawl occurred in such a rate that left little attention to the conditions that characterize the city core; the northern tip of the Abu Dhabi Island and the existing Superblocks. Consequently, this paper will attempt to study the historical background, the evolution and the existing situation of these Superblocks and highlight the uniqueness of their properties in terms of urban morphology since they differ significantly from other precedents like Cerda's Barcelona Plan, 'Le Corbusier's Ville Radieuse, the Radburn Superblock of Clarence Stein and Henry Wright and the Neighborhood unit of Clarence Perry that were prevalent in many post-WWII new town designs globally. ${ }^{2}$ It will then argue in favor of the necessity of a diverse regeneration strategy to prevent further weakening of the collective/ mnemonic layering of the city.

It aspires to be the launching pad of a series of pilot studies concerning the Superblocks that consist the island urban grid, being in full alignment with Abu Dhabi's 2030 Plan, its framework and policies. These pilot studies are instructed by the 2030 Plan as well. The benefits to Abu Dhabi can be anticipated at various levels: At an urban design level, the study analyses the existing situation and proposes pragmatic solutions for improving the urban environment. At a more strategic level, it provides all necessary input for an overall re-institution of Abu Dhabi's urban morphologies and improving the existing guidelines and standards. At an international level, Abu Dhabi's expectations to become a global center can be addressed, as this study hinges on - as its title implies the return of the modernist values into the Urban Design and Urban Planning theory and practice.

\section{Data Collection}

As a subject related to urban regeneration, the relevant data to be collected were divided to three major source groups: Bibliography, authorities and onsite observations.

Since Abu Dhabi's contemporary city is only almost fifty years old, the literature associated with its urban environment is limited. It was only recently that certain events boosted new literature and research efforts in the region: the creation of iconic buildings and housing developments, the welcoming of international events related to urban tourism, conferences etc. and the operation of major educational institutions - either independent or supported by state funding and international branching. Neighboring Dubai has been in the academic

1. Juan Busquets, Barcelona. The urban evolution of a compact city (Rovereto: Nicolodi/ Harvard University, 2005).

2. Nicholas Patricios, "Urban design principles of the original neighbourhood concepts," Urban Morphology 1 (2002): 21-32. 
research spotlight for a much longer time ${ }^{3}$ than Abu Dhabi, mostly due to its intricate and superlative ${ }^{4}$ character.

The absence of almost any collective memory connecting the city not only to its pre-oil past but also to its modernism samples built until the 1980s is highly criticized in literature of other Abu Dhabi Universities (i.e. New York University), launching a Cultural Heritage initiative for buildings to be demolished. The particularities of the Superblocks are highly affected by the waves of buildings "recycling" and the internal absence of a robust public space hierarchy. Other literature sources fill in this peculiar gap by introducing "informal" spaces and shedding light on their spontaneous but vital existence.

Superblocks however are not directly studied. All existing sources refer to them only superficially. This paper aims at presenting innovative work that may be used for producing pilot studies (as suggested by the Abu Dhabi 2030 Plan) and highlighting the underlying values of the modernist urban grid into its Arabic context.

Regarding authorities the Abu Dhabi Urban Planning Council (UPC) and its "Abu Dhabi 2030 Plan" accompanied by a diverse set of policies, guidelines and standards consists the Project's main reference source. Its flexibility in both strategic and zoomed-in scales provides further incentive for criticism and improvement. Other key authorities would be the Abu Dhabi Municipality (ADM) and the Tourism and Culture Authority (TCA), for reasons to be analyzed in due course. However, the UPC have been conducting an ongoing and quite analytical research on this very specific subject of the downtown urban regeneration since 2007. Their studies have been published into several reports, with only one of them being discussed in the public. ${ }^{5}$ These reports were denied from sharing, under the justification of exporting "sensitive" information. The quantity and quality of these data would piggyback this research in a profound way. In their absence though, different strategies - based primarily in observation data - would be followed, as it will be unveiled in the chapters to come.

\section{Methodology}

The methodology proposed to support the argumentation on the Superblocks' special origin and their potential contribution to the neighborhood regeneration efforts combines on-site observations and a juxtaposed set of historical information.

The historical information is divided in two parts: the one is related directly to Abu Dhabi's urban planning evolution. It presents a brief description of the key milestones that forged the urban fabric. The second part presents some highly

3. Yasser Elsheshtawy, The Evolving Arab City: Tradition, modernity \& urban development (London: Routledge, 2011).

4. Ahmed Kanna, The superlative city. Dubai and the urban condition in the early twentyfirst century (Cambridge MA: Harvard University Press, 2013).

5. Yasmeen Al Rashedi, The impacts and viability of urban revitalization in the city of Abu Dhabi, master's thesis (Abu Dhabi: Paris Sorbonne University, 2011). 
related international examples of urban planning, in terms of chronological continuity, theoretical framework similarity, geographical/climatic proximity and cultural identity.

The on-site observations are primarily focused towards a morphological analysis of the site and are escorted with some basic demographics, statistics etc., accompanied by all necessary theoretical framing.

The analysis presentation of conditions within specific Superblocks will also take place, in the argument's service. Hence, the outcome of the aforementioned historical juxtaposition will shape proposals for all levels of urban design (urban morphology, public space and streetscape). Combined with the introduction of further sustainability factors, implementation methods and funding opportunities may be examined.

All findings will then be used to introduce a new approach that may combine the latest retrofit practices with the Superblocks' regeneration initiatives. An approach that moves entirely on the urban scale, far outside the individual plot.

\section{Urban Evolution}

Abu Dhabi's shallow urban history was replenished by an oil revenue driven growth frenzy. This transition from an ephemeral fishing village to a highly recognizable international hub has just recently started been examined by scholars. Its growth rate in terms of elapsed time, population, urbanized area, services provided and expectations reached may be compared even to human/biological equivalents (Figure 1). Although it's not the main subject, Abu Dhabi's planning evolutionary history will be analyzed only to the extend and direction that fits and serves the context: The urban form, the evolution of the morphological and spatial elements of the built-up and open areas of the city, the forging of the superblocks and the powers that contributed to that shall share the spotlight of this review.

The currently bustling metropolitan island of Abu Dhabi was only recently a small remote fishing village with just a few permanent dwellers. The scorching temperatures, the humid climate along the coast of the Arabic Gulf and the lack of fresh water were prohibitive enough. The earliest signs of any human settlement in the island go back to 1761, while in 1793, Sheikh Shakhbout bin Dhiyab bin Isa - the leader of the Bani Yas tribe - being skeptical about the advancement of the Wahhabi forces of Saudi Arabia, he led his people from Liwa and Dhafra to this settlement at the northern tip of the Abu Dhabi island with the newly discovered source of fresh water that spurred interest. The village grew up fast to become a permanent settlement. ${ }^{6}$

6. Abu Dhabi Municipality (ADM), Abu Dhabi, Dana of the Gulf (Abu Dhabi: ADM, Planning and Urban Development, Studies and Research section, 2003), 21. 


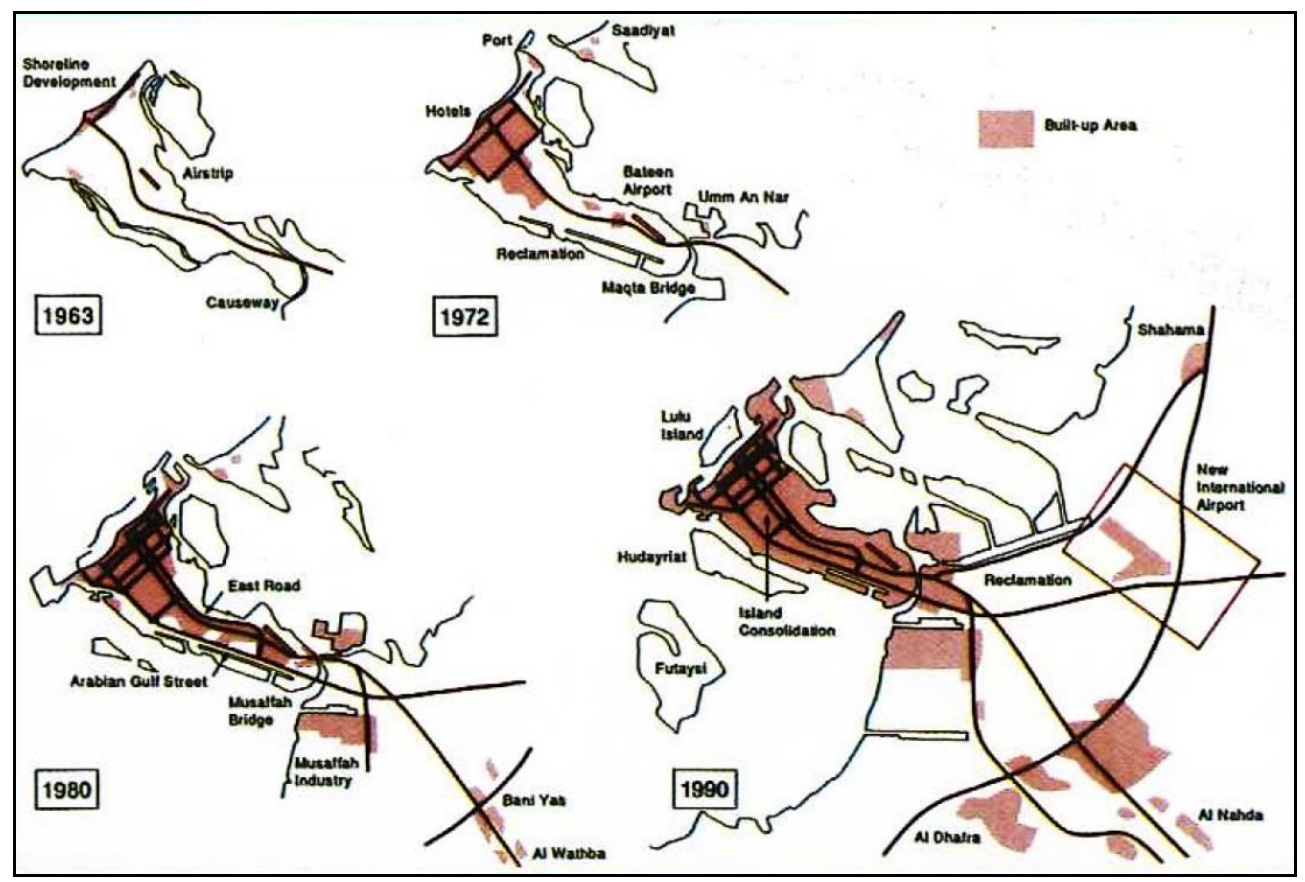

Figure 1. Abu Dhabi's Urban Evolution, 1960-1990

Source: ADM, 2003:30.

The Sheikh also ordered the construction of his new fort, primarily made of stone and corals. It was Qasr Al Hosn, the only remaining pre-oil building in Abu Dhabi, which stood out from the rest of the village as a landmark. All other buildings were built by mud and palm fronds forming rectangle cabins with small courtyards in between - also known as barasti. Most of them were positioned in small groups or clusters according to different tribes and families. Furthermore, small narrow streets (sikkak) were dividing these groups of barasti in a random - organic way, leading to the Fort and to other facilities (the souq etc), while oriented towards the north to take advantage of the cool breeze. ${ }^{7}$

Sheikh Shakhbout was the Emirate's Ruler in 1953, when the first oil concession was signed. The first shipped oil consignments took place in July 1962 and December 1963 (from Das island and the Bab inland field respectively). However, despite everybody's aspirations, Sheikh Shakhbout kept a rather conservative stance and offered a disproportional low number of much needed facilities. ${ }^{8}$ The continuation of the denial for development reached a critical point and the dead-end was interrupted by Shakhbout's brother, Sheikh Zayed bin Sultan Al Nahyan who became the next Ruler of the Emirate. His foresight was key to the shift of Abu Dhabi from a local fishing post to a major capital city of the world. Sheikh Zayed criticized ${ }^{9}$ and rejected both existing plans (by

7. Abdelrahman Makhlouf, Life Journey with Urbanization: Documenting the heritage of Abu Dhabi's urban development during the period from 1968 to 2014 (Beirut-Lebanon: Arab Office for Architecture and Planning, 2015).

8. Mohammed Al Fahim, From rags to riches; A story of Abu Dhabi, 2nd Edition (Abu Dhabi: Makarem, 2013).

9. Portal 9, Plans the Earth Swallows: An Interview with Abdulrahman Makhlouf (Issue 2, Spring 2013) http://portal9journal.org/articles.aspx?id=92. 
Harris and Halcrow, in 1962), implementing an amendment by Arabicon by using a grid-iron road network in an attempt to provide as much new available land as possible. The pre-oil settlement was demolished and its dwellers were compensated. Furthermore, Sheikh Zayed distributed to each Emirati three plots in the island, allocated for residential, commercial and industrial use each, in an unprecedented gesture of generosity. ${ }^{10}$ The commercial plots especially with dimensions of $200 \times 100$ feet $(61 \times 30.5 \mathrm{~m})$ - were provided along the main highways (i.e. Hamdan street), thus forging today's downtown morphology. ${ }^{11}$

Later on, the Japanese engineer Takahashi assumed a leading town planner position in Abu Dhabi, providing a new Master Plan with a considerable extension of the urban area to the south to accommodate a series of new uses and vital infrastructure, clearly inspired by Arata Isozaki's utopian "City in the Sky" project. $^{12}$

The major cultural gap led to the replacement of the lead urban planner of the city and to Abdelrahman Makhlouf. The Egyptian planner spoke in the proper language not only to the officials' ears but also to their emotional and cultural properties and desires. He proposed a neighborhood unit with low-rise residential use and all necessary community facilities (Figure 2): "I made a social plan for how we would fill Abu Dhabi's grid with housing. Each unit had seven houses. The plan was made so that neighbors from the same block could sit together after evening prayers. My plan reflects their traditions. You don't have to walk far to visit your family, and you had all your services, including the mosque and school, nearby." 13

Makhouf introduces the Sha'abiyat, ${ }^{14}$ the typical Emirati housing units, as a reinterpretation of the traditional Arabic courtyard house. However, the transition to the western villa was fast and complete as all traces of the traditional houses soon became obsolete. His own Master Plan for Abu Dhabi, called the "Guiding Concept Plan" includes the already formed grid-iron layout until today's Falah Street, some new residential hubs (in Al Rayhan and Rawdhat areas) and an elongated dense commercial corridor along the Airport road axis, isolated though from any residential context. Makhlouf also produced a series of plans and models that would articulate his thoughts on the downtown area and would reflect Sheikh Zayed's vision. He designed various public buildings and the whole urban form of these central blocks: Their inside would be based on the aforementioned "neighborhood unit" with G+2 floor houses, while the outline plots would assume a commercial (primarily) use, with heights of up to 10 floors. Again, his modernistic approach on a linear, functional plan would meet Sheikh Zayed's aspirations for equity (among land-receiving Emiratis),

10. Al Fahim, From rags to riches; A story of Abu Dhabi, 2013.

11. Portal 9, Plans the Earth Swallows: An Interview with Abdulrahman Makhlouf, 2013.

12. Kais Samarrai, "The evolution of Abu Dhabi City's urbanization and the sustainability challenge," in Shaping Cities; Emerging models of planning practice (ed.) M. Al-Asad and R. Mehrotra (Berlin: Hatje Cantz, 2016).

13. Portal 9, Plans the Earth Swallows: An Interview with Abdulrahman Makhlouf, 2013.

14. Pascal Menoret. The Abu Dhabi guide. Modern Architecture 1950s-1990s (Abu Dhabi: Menoret Pascal, 2014). 
urgency and continuity, to forge Abu Dhabi's signature urban pattern, the Superblock.

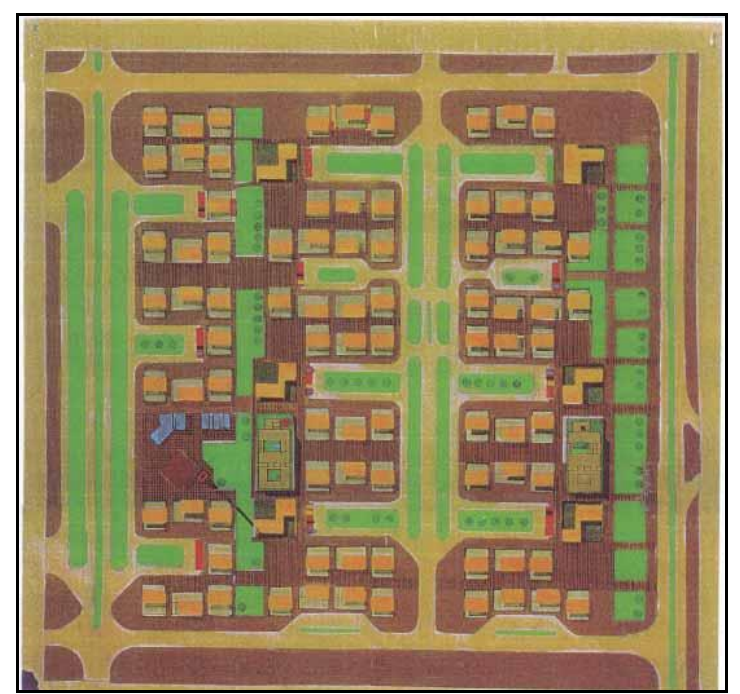

Figure 2. Layout of a "Social Neighborhood Unit"

Source: by Dr. Makhlouf (Portal9, 2013).

In 1971 the Federal nation of the UAE was formed - under Sheikh Zayed's leadership. Seven Emirates united their strengths under the fear of a potential Saudi Arabia threat and the simultaneous withdrawal of the British colonial forces. Abu Dhabi became the capital city of the country in both an Emirate and Federal level. This added both international recognition and a necessity to incorporate all government facilities to the city plan.

Abu Dhabi's growth reached unprecedented rates, especially after the 1973 war between Egypt and Israel that increased the oil prices. Within four years, a significant excess of supply in the housing sector of merely 15,000 empty apartments - most of them in the high-rise buildings at the superblock outlines - caused a development slowdown in 1977 that forced Sheikh Zayed to order a construction ban. ${ }^{15}$

Combined with a series of poor management of the gifted plots by the Emiratis, the government decided the establishment of the Khalifa Committee, named after the son of Sheikh Zayed, Khalifa, Crown Prince at that moment and President of the UAE today. The Khalifa Committee would distribute, develop and manage the allocated plots on behalf of the Emiratis. After achieving adjustments on the maximum building heights, they were able to construct almost two hundred buildings every year, until the early 1990s, thus addressing an increase at the housing needs. These massive numbers were achieved under a strict budget and standardized and almost repetitional layouts and elevations of up to twenty floors. ${ }^{16}$ Much of Abu Dhabi's existing building stock belongs

15. Elsheshtawy, The Evolving Arab City: Tradition, modernity \& urban development, 2011. 16. Ibid. 
to this act, forging today's superblocks and a critique regarding the aesthetically bland and banal urban morphology. ${ }^{17}$

It was the year 1988 when the growth frenzy forced the government to control the urban growth, by producing the first Comprehensive Master Plan for Abu Dhabi. The assistance of UNDP and Atkins was requested. The new plan was called "Master Directive Plan for Abu Dhabi and its Environs, 1990-2010". According to that Plan, many downtown plot sizes were reviewed, henceforth allowing the merging of small plots to bigger ones, in order to accommodate more functional layouts. ${ }^{18}$

The last layer of urban evolution - still running today - was formed in 2004 with the passing of Sheikh Zayed and his replacement by the much more ambitious son of his, Khalifa. The 9/11/2001 incident and a series of major reforms on major developers and an Urban Planning Authority (UPC) led to today's analytical framework for the city. Sustainability was the new key word, accompanied by the Cultural element, as a profound part of the city's identity. It is since that point that the regeneration of downtown Abu Dhabi is recognized as an issue of vital importance for the preservation of a specific level of urban quality that could be jeopardized or overlooked by focusing development on the periphery.

\section{The Superblocks - A Parallel Story}

The Superblocks, Abu Dhabi's distinctive urban pattern in its downtown area, were created primarily by adjusting Makhlouf's "Neighborhood Unit" to the primary Halcrow plan and expanding in a repetitive way due south-east according to the Takahashi - Makhlouf plans. This pattern is highly evident in the main island, especially on its northern half. Interestingly though, this pattern is skewed and adjusted to both the curvy shapes of the eastern coastline and other space-demanding areas (Figure 3).

17. Samarrai, "The evolution of Abu Dhabi City's urbanization and the sustainability challenge," 2016.

18. Ibid, 110. 


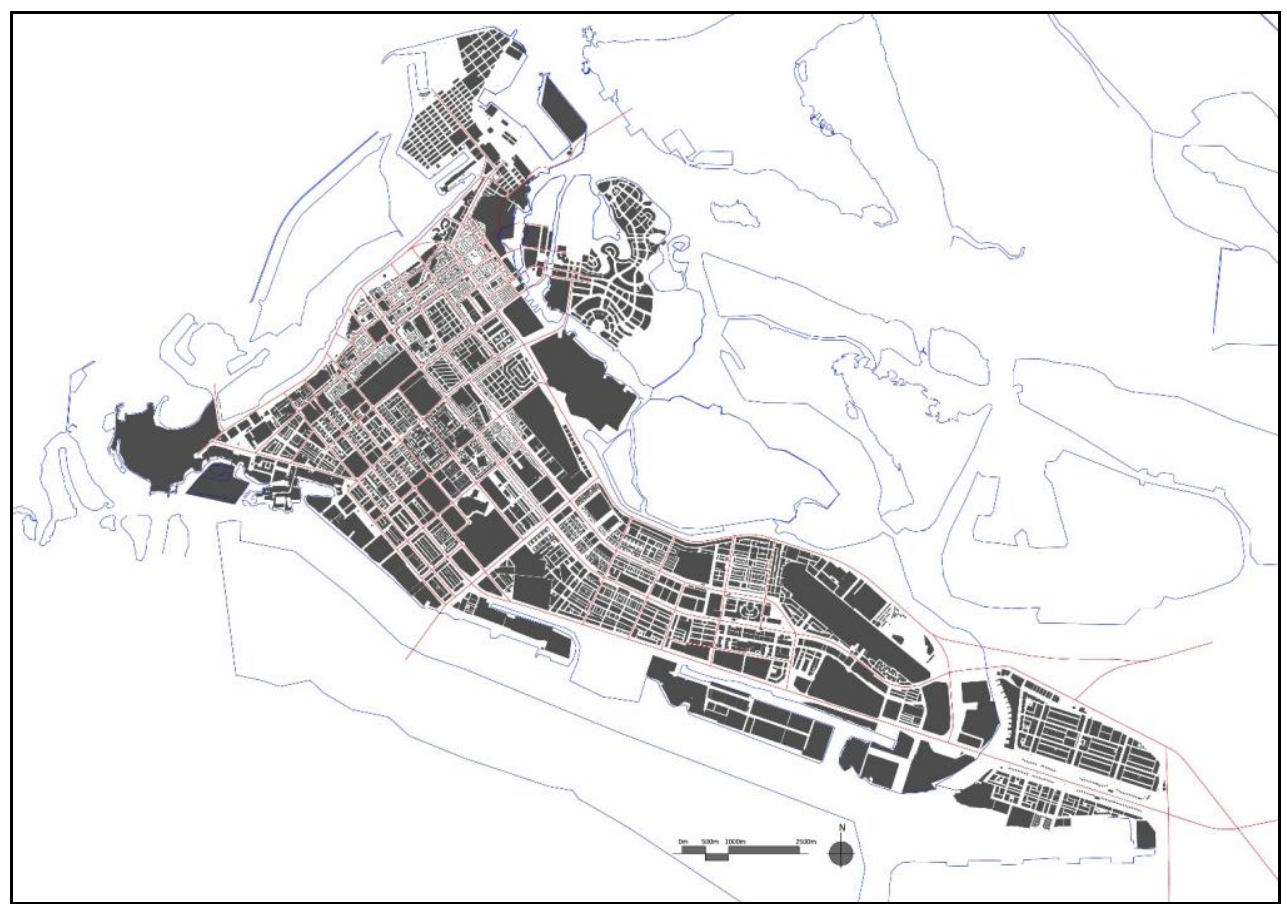

Figure 3. Abu Dhabi's Urban Layout in 2016 (The Island Part)

Source: Author.

The name "superblock" derives from its size. Being considerably bigger than ordinary city blocks, they are consisted of an outline array of high-rise buildings (mostly mixed use) and of an inside pattern of lower height buildings of - mostly - residential use. They are divided by urban highways, major dualcarriage way streets of 6 lanes minimum (in total). Its average dimensions ${ }^{19}$ are $500 \times 700 \mathrm{~m}$ ( or $350,000 \mathrm{~m}^{2}$ or $350 \mathrm{Ha}$ ), with building' heights of 20 floors at the perimeter $(70 \mathrm{~m})$ and $12 \mathrm{~m}$ on the inside.

So it seems that the Abu Dhabi's superblock model seems to be a whole new entity. Its uniqueness is not because of its street network but of its binary morphology that resembles a fruit (with a high-rise "peel" and a less dense inner part), in combination with its external dimensions. These properties took shape after Sheikh Zayed's policy of providing three pieces of land (residential, commercial and industrial) to all Emirati citizens of Abu Dhabi and of course the implementation of the early master plans for the city (Halcrow's revision by Arabicon and the Takahashi - Makhlouf plans). Equity was one factor of this equasion, with speed (of implementation) and efficiency (of both in resolving issues of that time and in its expansion ability in the future) being the other two. ${ }^{20}$ Regarding equity, all plots donated by Sheikh Zayed and the Khalifa Committee had equal sizes among the recipients. Actually, this cherished characteristic is a prerequisite even for contemporary development submissions regarding the national housing program (for Emiratis only).

19. This research selected the superblock within the streets: Airport, Falah, Muroor and Hazza as the one that could represent an average external dimension.

20. Portal 9, Plans the Earth Swallows: An Interview with Abdulrahman Makhlouf, 2013. 
Is this pragmatism though reflected to any of the early conceptual design stages for Abu Dhabi's superblocks? Or has it derived from the mind of a gifted leader alone? Zayed requested that speed, being aware that Abu Dhabi was less modernized in relation to other GCC cities (i.e. Dubai, Manama etc.) and that Abu Dhabi, its citizens and investors were urging for a rapid adaptation to the new condition. Makhlouf on the other hand used his Neighborhood Unit as the main urban pattern out of which today's superblocks emerged - despite his denial on that. ${ }^{21}$ Indeed, the Neighborhood Unit is remarkably similar to the existing situation of most of the superblocks. But, how unique a feature the Abu Dhabi Superblock really is? Is it possible that this implementation pragmatism could be accompanied by an inspirational import on a design level?

The introduction of Makhlouf's Neighborhood Unit as Abu Dhabi's main urban pattern coincides with a similar nearby development. Konstantinos Doxiadis - the first global urban planner according to Rem Koolhaas ${ }^{22}$ - was already famous for his master planning works for Baghdad, Islamabad, Saigon etc., his direction of the Greek post-war housing program, his contribution to numerous United Nations and World Bank urban planning and housing missions across the Middle East23 and of course for his theoretical work on Ekistics, the science of human settlements, a dynamic interpretation of the modernist urban planning approaches, ${ }^{24}$ when he was assigned to design the Master Plan for neighboring Riyadh. The project initiated in early 1968 and was officially presented in 1971. Prior to that, his plans for Baghdad (1958) and Islamabad (1960) were equally influential. These three examples are mentioned on purpose, since they yield specific urban characteristics (as part of his Ekistics cosmotheory) with stunning similarities not only amongst each other but also to Abu Dhabi's superblocks.

Doxiadis worked for Baghdad from 1955 to 1965. In his master plan officially submitted in 1958 - he created a modular grid that moved parallel to river Tigris, with each module having a central core with flexible building types and uses. At the center of this grid, he used his famous "dynapolis" open-end $\operatorname{axis}^{25}$ to channel urban expansion (Figure 4). Regarding the modules neighborhoods, Doxiadis cooperated with the famous Egyptian vernacular architect Hassan Fathi to design cozy low-density superblocks for the Iraqi lower classes adorned with "gossip squares" that were intended to promote social cohesion by recreating a village environment. ${ }^{26}$

21. Ibid.

22. Rem Koolhaas and H. U. Obrist, Project Japan: Metabolism Talks (Taschen, 2009).

23. Syria, Jordan, Iraq, Lebanon, Iran, Pakistan, Saudi Arabia, Sudan and Libya were the countries included in the UN-WB programs.

24. Constantinos Apostolos Doxiadis, Ekistics. An Introduction to the Science of Human Settlements (New York: Oxford University Press, 1968).

25. Ibid.

26. Pascal, The Abu Dhabi guide. Modern Architecture 1950s-1990s, 2014. 


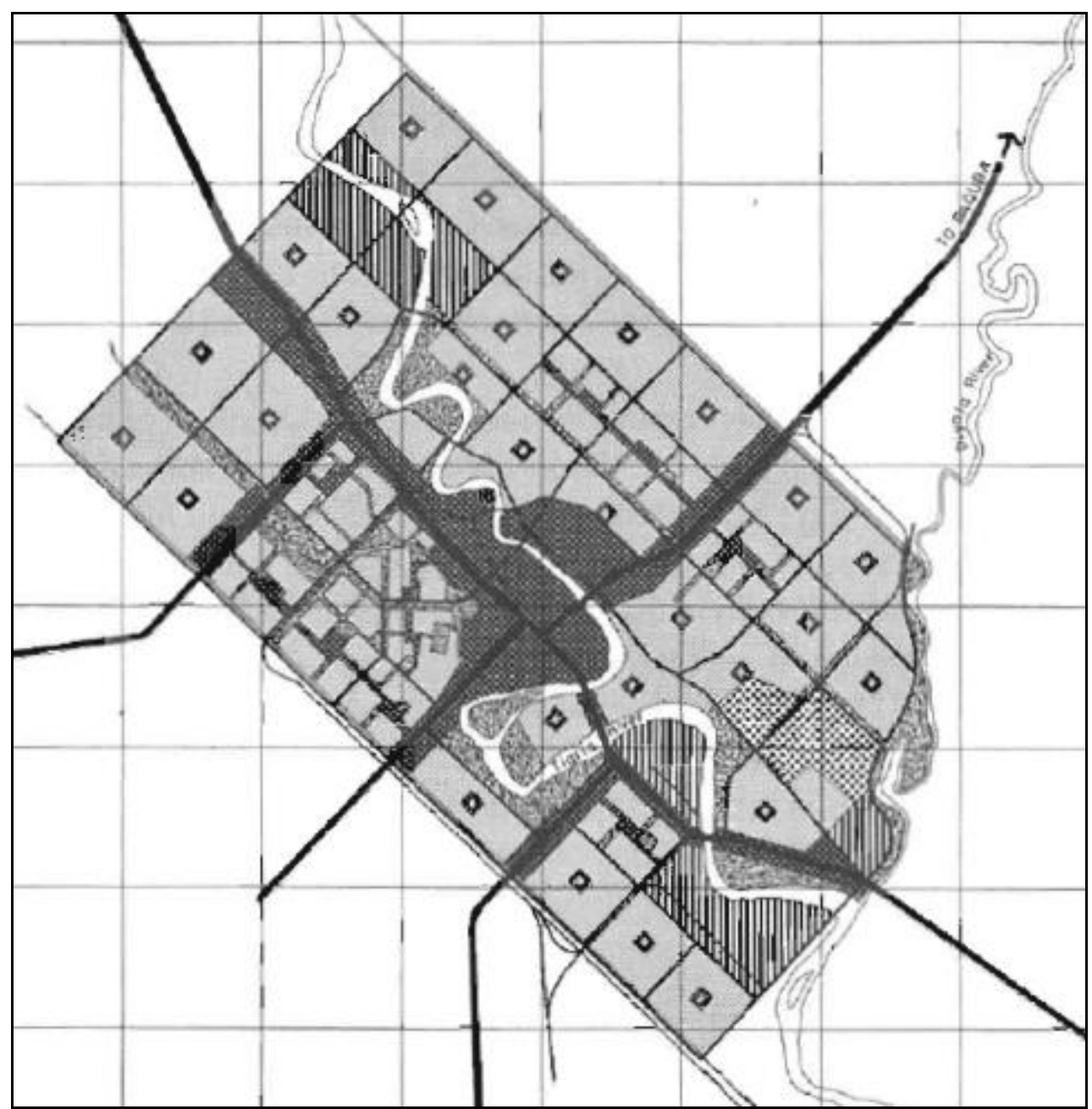

Figure 4. Doxiadis' Master Plan for Baghdad in 1958. The Open-end Corridors and the Neighborhood Module Grid that Adapts to Tigris' Meanders are Visible.

Doxiadis moved to his next challenge to create Pakistan's new capital city in 1959. The plan for Islamabad constituted the closest depiction of his "dynapolis" diagrams but was criticized for not providing low-income housing. Being a city designed and built from scratch it made its characteristic grid show up in full display. The modules were $2 \times 2 \mathrm{~km}$ wide, surrounded by highways. ${ }^{27}$ There were limited entrances to each side leading to the civic services core, separated networks for pedestrians (whenever possible through the exploitation of topographical features like rivers etc.) and service roads to serve the external plot land uses (usually civic or commercial) running parallel to the highways (Figure 5).

27. Deborah Middleton, Growth and Expansion in Post-War Urban Design Strategies: $C$. A. Doxiadis and the First Strategic Plan for Riyadh Saudi Arabia (1968-1972), PhD Thesis (Georgia Institute of Technology, 2009). 


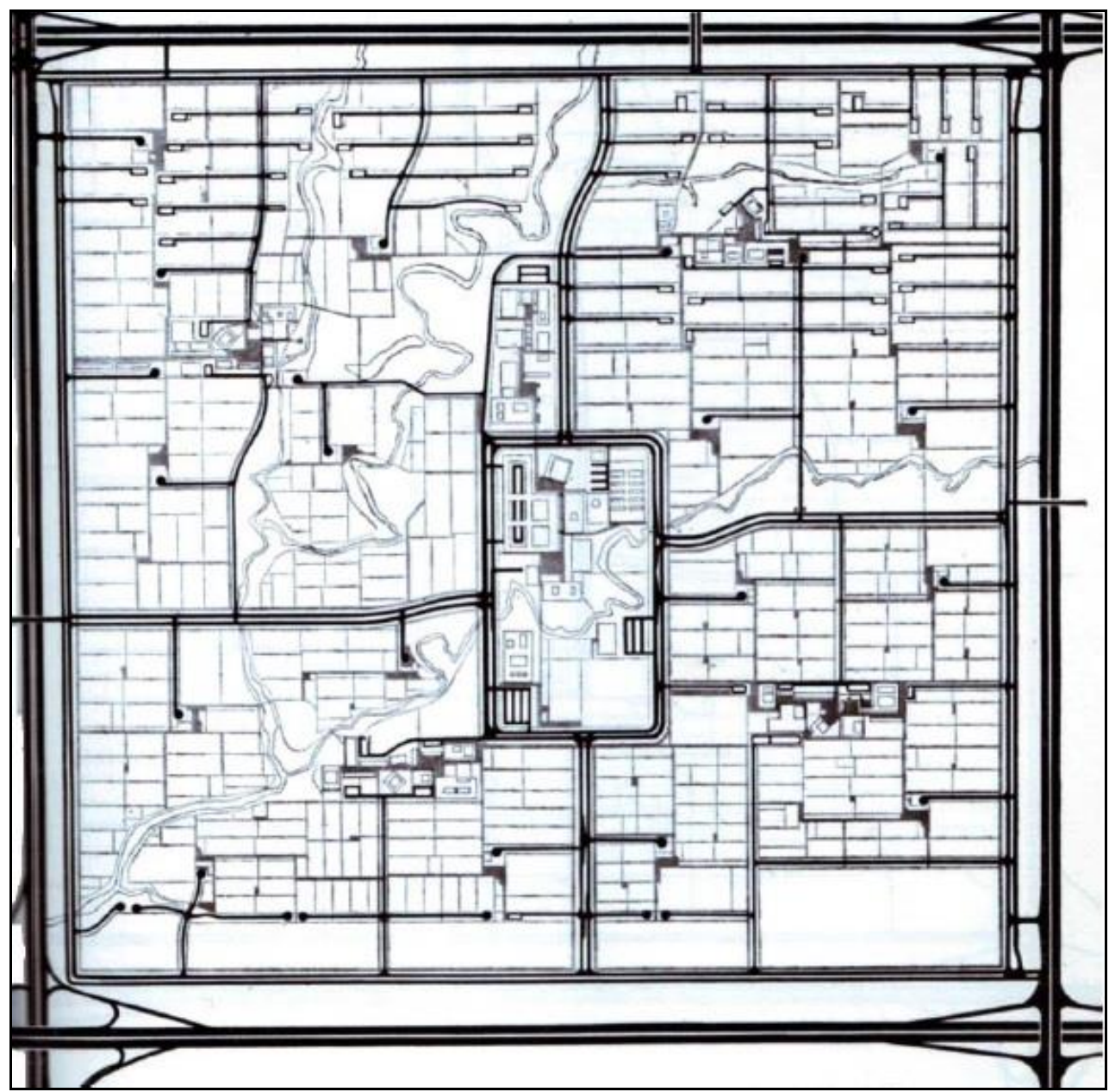

Figure 5. The Islamabad Urban Module

Source: Middleton, 2009.

In Riyadh's case, Doxiadis had to initiate the Master Plan project by incorporating the same highway grid philosophy to an existing agglomeration manifested through a similar urban module and an open-end axis (the King Fahd highway - Olayya street spine). The residential neighborhoods - modules were once more almost $2 \mathrm{~km}$ long (1.2 miles) and were designed as "self-sustained communities with shops, schools, mosques, parks etc." 28 Drive-through traffic was avoided, with the absence of cross-road junctions on the local roads being a major contributor to that. ${ }^{29}$ Instead, the streets meet at the module's core creating a central open space rectangle, a layout also known as a "mafruka". This layout

28. Menoret, Pascal, Joyriding in Riyadh. Oil, urbanism and road revolt (New York: Cambridge University Press, 2014), 99.

29. Apostolos Kyriazis, Evgenios Balassis and Nikolaos Patsavos, "Housing in the sand and social inertia; A case study from Saudi Arabia," pres. at the Housed by choice, housed by force, in AMPS Conference Publication Series 5. Housed by Choice-Housed by Force - Homes Conflicts and Conflicting Interests (ed.) G., Artopoulos, C. Hadjichristos and G. Cairns (Nicosia: University of Cyprus; The Cyprus Institute, 2016), 80-90. 
is repeated at each quadrant created, shaping a pattern with a seemingly fractal logic (Figure 6).

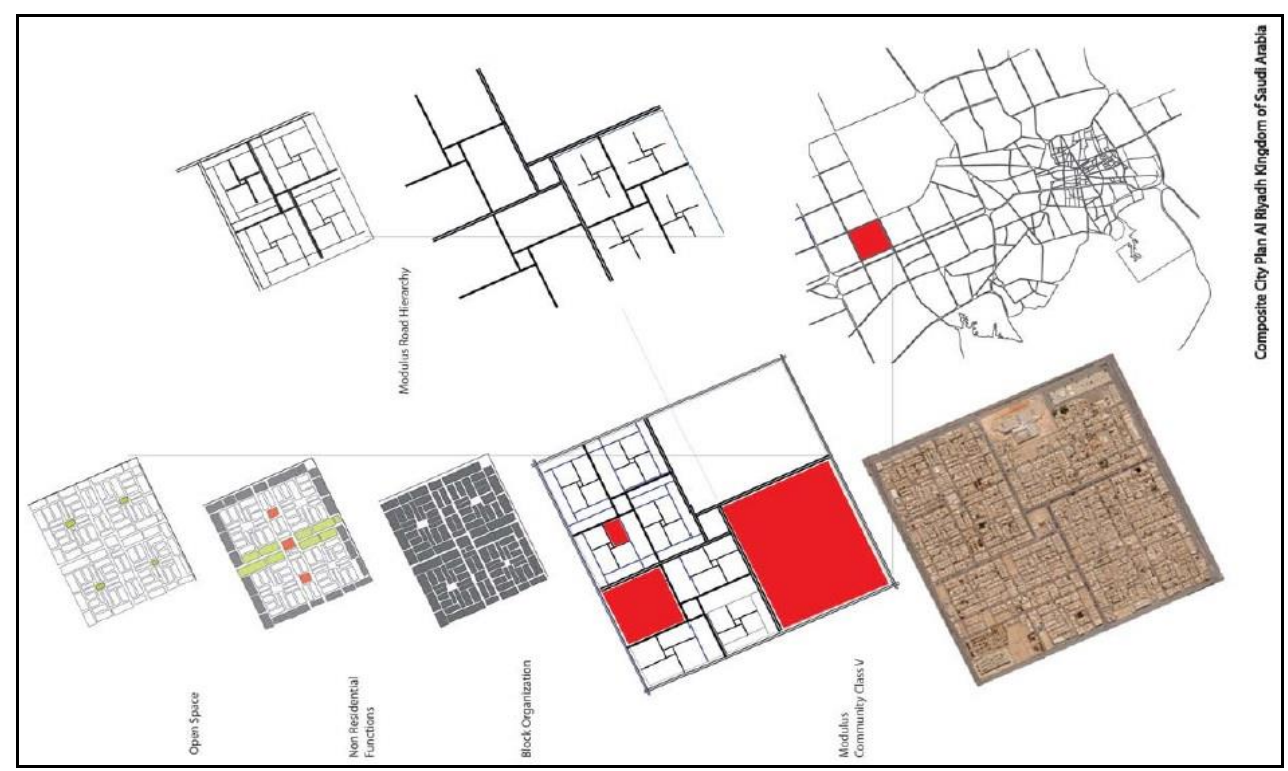

Figure 6. A Superblock Module Analysis

Source: Middleton, 2009.

Quite remarkably, it is also in Riyadh's superblocks that all external plots accommodate more uses (i.e. commercial, offices etc.) in contrast with the residential-only interior. The densities and building heights are also regulated respectively. ${ }^{30}$ The Doxiadis' plans regarding the superblock module were again criticized for their lack of personality and identity. Furthermore, regarding the Riyadh example, the plans' implementation rapidly passed back to the hands of the few and were significantly altered. As far as the modules are concerned, the pedestrian corridors connecting the module cores never took place. The car dominated especially the outline (along the highway grid) but also the interior of the modules, as an outcome of Saudi Arabia's cultural particularities. The emphasis to the outside layer of the module became so prominent that led to overlooking and deterioration of the more "private" interior.

\section{A New Condition for Abu Dhabi's Urban History}

In the need to close this parenthesis regarding the possible relation between Doxiadis' master plans for Baghdad, Islamabad and Riyadh and the origin of the Abu Dhabi Superblock as designed by Makhlouf, certain comments ought to be made:

30. Middleton, Growth and Expansion in Post-War Urban Design Strategies: C. A. Doxiadis and the First Strategic Plan for Riyadh Saudi Arabia (1968-1972), 2009. 
- This paper only remarks and pinpoints the conditions under which this coincidence took place. One of them is about the timing. Baghdad and Islamabad were designed and implemented prior to Abu Dhabi, while Riyadh was unveiled almost in parallel.

- These three cities and especially Islamabad were celebrated as major modernist paradigms of an Islamic City. ${ }^{31}$ Interestingly, Makhlouf insists on Abu Dhabi's identity as an Islamic and not an Arabic city. ${ }^{32}$

- The involvement of the Egyptian architect Hassan Fathi at the Baghdad's master plan and namely the design of the residential modules increases the possibilities of an interaction with the also Egyptian Abdelrahman Makhlouf.

- The introduction of the western villa as the prevailing low density residential feature in Makhlouf's Neighborhood Unit is sudden but anticipated, as being consistent with Sheikh Zayed's spirit and intentions of eradicating the old and embracing a new, modern identity for the Emirate's capital city. The villas' distribution was based on the existing tribal structure of Abu Dhabi's residents ${ }^{33}$ and was reflecting the Islamic values of socializing. ${ }^{34}$ At the same time, almost all related literature fails or neglects to explain the profound reasons for the sudden and peculiar - in terms of climatic conditions and cultural, social or religious principles - shift from the "barasti" and "fareej" housing model to the single plot - single villa model. Menoret ${ }^{35}$ argues that it was Aramco's first American high officials and engineers in the late 30 's that demanded to be accommodated in such houses, due to lack of proper living conditions. The imported western villa type was slowly appreciated by the Saudis as a mark of status and prestige. This is vividly portrayed in the first planned urban neighborhood of Riyadh, Al Malaz, which was designed in 1953 (15 years before Doxiadis' arrival) for high-income expatriate employees. However, apart from this reference, little is known regarding the reasoning and precise timing of this shift in most of the GCC cities.

- The designed and implemented urban form of the Superblock samples from all cities aforementioned regarding both the overall image and the individual elements (i.e. the buildings' morphology, the produced urban tissue, the land uses and the road layouts) can be characterized by a remarkable resemblance that goes beyond the essentials of modernism in the urban scale. Besides, Doxiadis was the one to master the Superblock notion, as a means to tame the transition from the mega-scale of the metropolis to the human scale of the residential cluster.

31. Ibid.

32. Portal 9, Plans the Earth Swallows: An Interview with Abdulrahman Makhlouf, 2013.

33. Elsheshtawy, The Evolving Arab City: Tradition, modernity \& urban development, 2011.

34. Portal 9, Plans the Earth Swallows: An Interview with Abdulrahman Makhlouf, 2013.

35. Menoret, Joyriding in Riyadh. Oil, urbanism and road revolt. 2014. 
This paper may only assume or at the worst case scenario hypothesize the existence of an influence or an inspiration by the pioneering plans of Doxiadis for the Abu Dhabi plans of the Superblock. Such a contingency though would have the power to provide further added value to the evolutionary urban planning history of Abu Dhabi. An interesting element to be further examined with regards to emphasizing on building up a new, unforeseen property of the city of Abu Dhabi. A brief but unique and highly dynamic history.

\section{A Case Study}

As mentioned at the introduction, this paper will focus primarily on the downtown area of the city - the northern half of the island - and more specifically the Superblock that is described by the streets Airport, Falah, Muroor and Hazza. A number of reasons justify this choice:

- The apparent clarity of the superblock form as explained earlier.

- The existence of the downtown area of Abu Dhabi.

- High densities (the highest of the city) and the presence of tall structures.

- Land use diversity, both vertically (in separate floors, within buildings) and horizontally (from plot to plot).

- A constant reference within all related UPC manuals and plans as the area destined for regeneration initiatives.

In Figure 7, the Superblock (enclosed in a red rectangle) is only one of the many that consist the key characteristic of Abu Dhabi's urban tissue. The clarity and the repetition of this urban form is more than obvious.

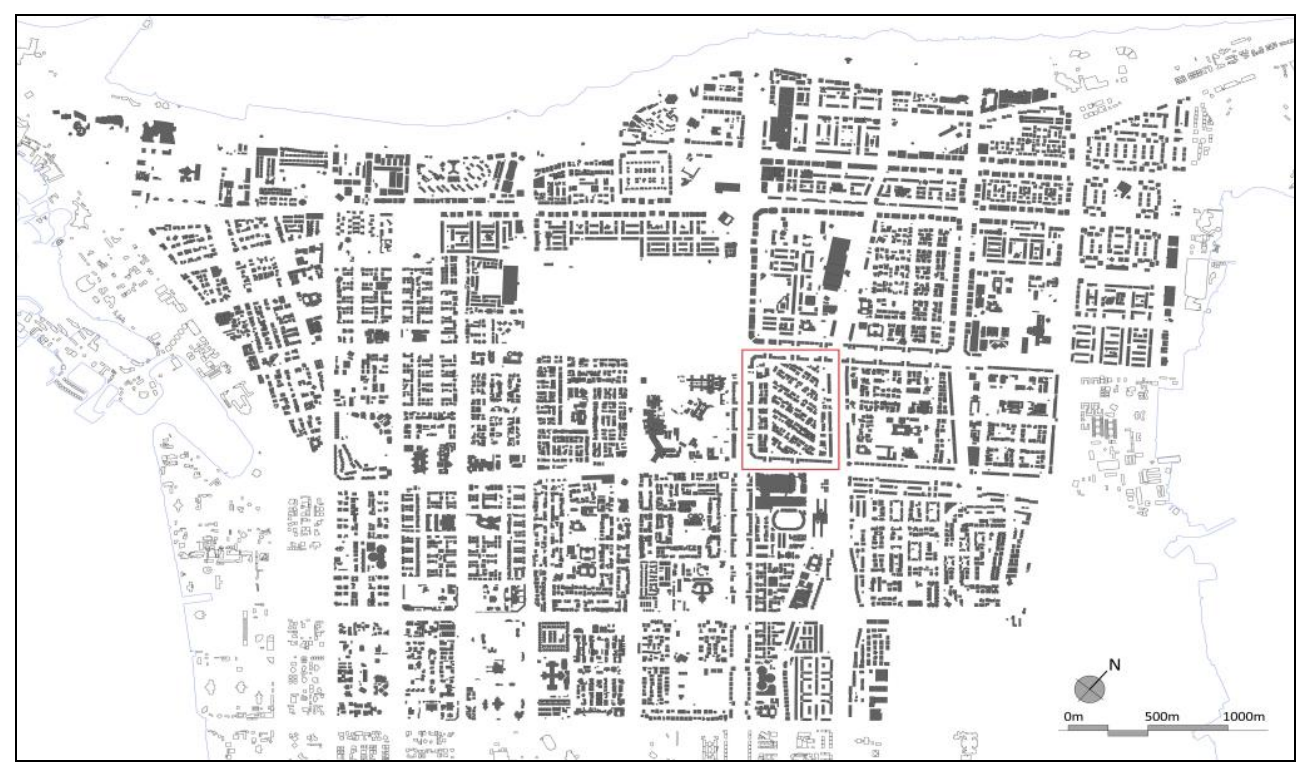

Figure 7. The Northern Half of the Abu Dhabi Island with the Selected Superblock Source: Author. 
A brief description of the block was made earlier. What's important is that a first glimpse of the Abu Dhabi's built-up area morphology doesn't only highlight the superblocks as legible entities but also presents them like a set of urban canvases: Most of them share the same "watermelon" identity (an external row of buildings that functions as a distinct "skin" that frames, protects and bubbles the lower-height interior), but their interior patterns are singular, like being created by different planners as part of an internal exercise of an urban workshop.

The selected Superblock is the only one with a rotated interior that doesn't align to the external edges. A first assumption regarding the resonate hidden behind this gesture could be the alignment of all internal plots (and consequently buildings) to the North orientation, in order to harvest the most of the sunlight on the streets, the best of the housing orientation, the best for aligning the Mosques to the grid (the Qibla line in Abu Dhabi is almost parallel to the North) and the optimum for catching the prevailing northern winds (Figure 8).

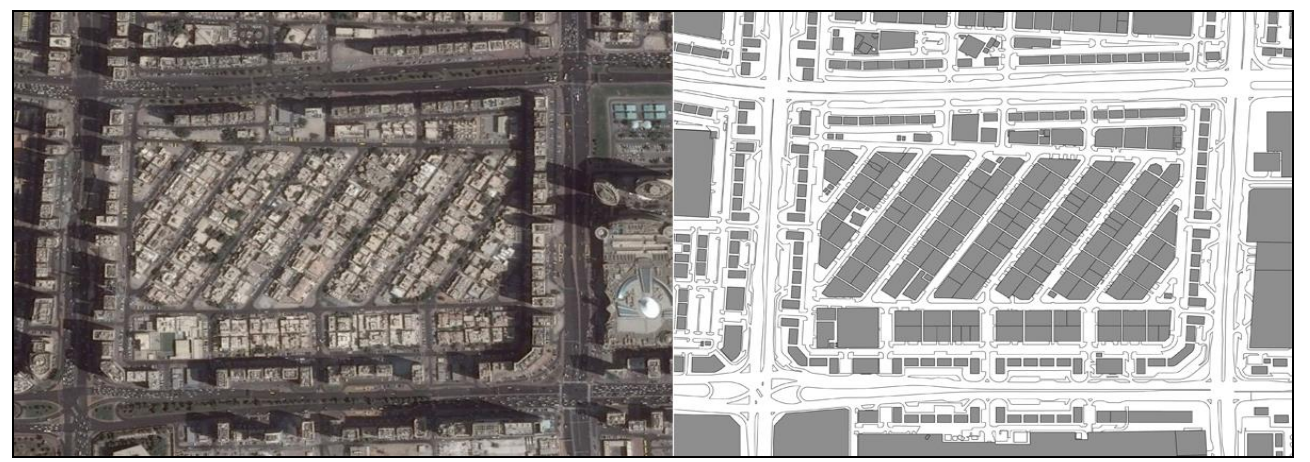

Figure 8. The Chosen Superblock, Showing its Typical Properties both in a Google Earth Image and in Plan

Source: Author.

However, it is not just the urban form that generates the "watermelon" effect. It is also the heights and the land uses. As shown in Figure 9, the key signature is also imprinted into these fundamental morphological factors.

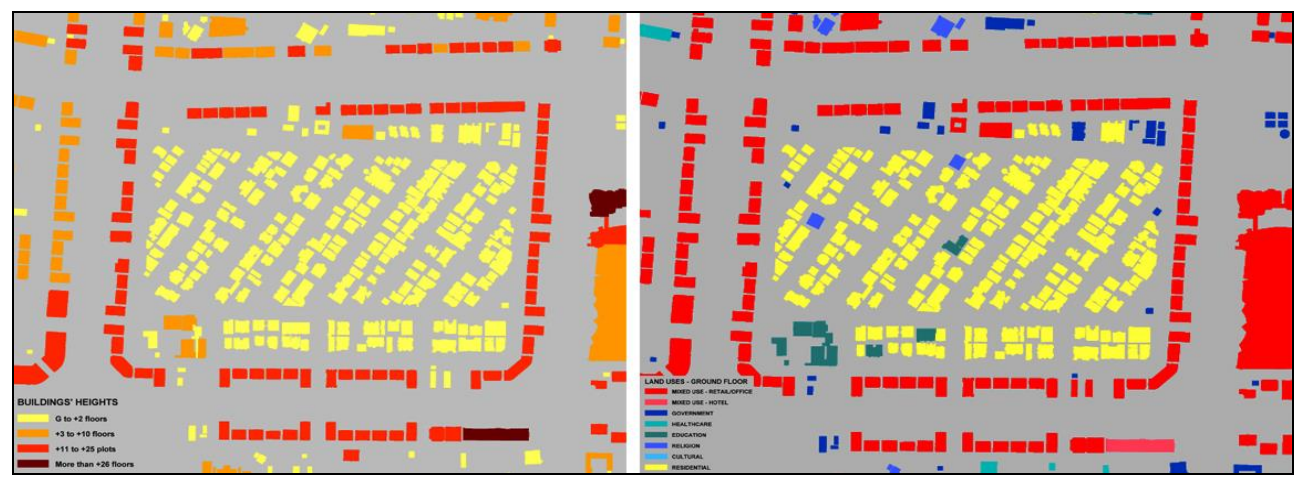

Figure 9. Maps Showing the Existing Buildings' Heights and the Ground-floor Land Uses within the Selected Superblock

Source: Author. 
The clarity of this feature is not totally consistent in all Abu Dhabi superblocks, but it's easily recognizable even to the most unfamiliar with notions of urbanism person, evident and distinctly prevailing in the areas that is needed the most: the dense part of the city, the north-eastern tip of the Abu Dhabi Island (Figure 10).

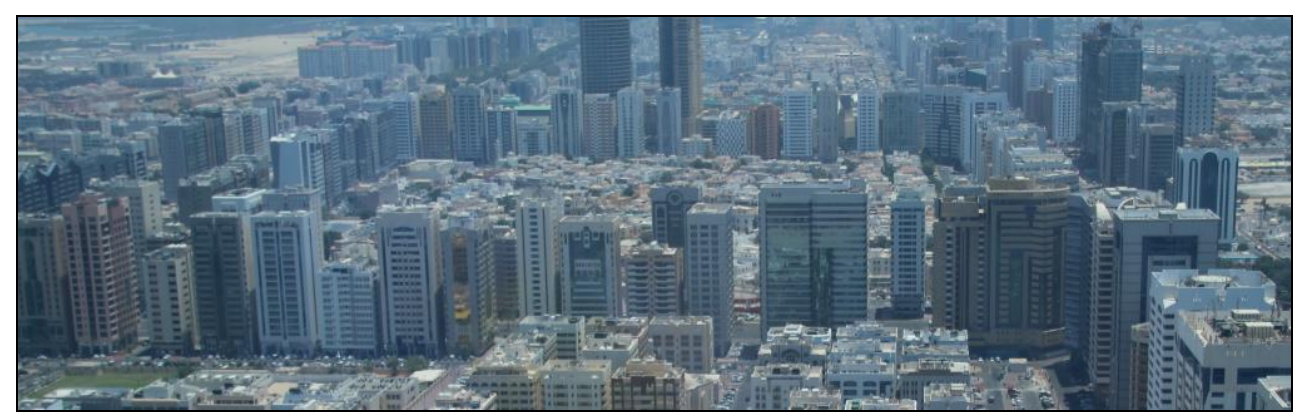

Figure 10. The Selected Superblock as seen from an Angle. The "Watermelon" Feature with the Outlining High-structure Envelope and the Low Interiors is easily Recognizable.

Source: Author.

\section{Superblocks Regeneration and Building Retrofit Initiatives}

It is fortunate though that despite Abu Dhabi's shallow history and rapid development, the city's Strategic Plan (Abu Dhabi 2030 Framework Plan) acknowledges the necessity of regenerating the downtown areas, the Superblocks. A whole chapter of the 2030 Plan in both the general description (chapter 7.6) and the detailed policies (Appendix V, chapters B33 to B37) is dedicated to this initiative.

The UPC has arranged for the creation of a specific research team dedicated to study the CBD revitalization. Since 2007, several reports have been issued by the team to be announced and discussed only internally, with the exception of an early report that is embedded in the Framework Plan and that was also communicated with the Emirati owners of the buildings to be found in the proposed Superblocks. This report proposed: ${ }^{36}$

- To put all parking underground or in dedicated structures.

- To make some through-roads to help relieve traffic pressure from the surrounding boulevards.

- To develop an interconnected public open space network.

- To identify new infill building possibilities.

- To add needed services and amenities to ensure vibrant inhabilitation.

- To design a coherent public realm.

36. Abu Dhabi Urban Planning Council (UPC), Abu Dhabi Plan 2030, Urban Structure Framework Plan, 2007. [Accessed March 2017]. 
However, for a variety of reasons dealing with high costs (connected to the plunging oil prices), technical drawbacks (high costs of underground parking due to the shallow acquifiers) and reactions from the owners themselves, this initiative and all reports issued henceforth until today by the UPC research team have been rejected. As mentioned in the Data Collection chapter, all these reports were displayed, discussed and shown to the author but were denied to be provided as a hard copy for the needs of this research project due to the degree of "sensitive information".

Indeed, most of these reports - especially the most recent ones - were fully detailed regeneration projects with an astonishing amount of information regarding the ownership status and all technical and planning parameters of all buildings involved into the processes. This in-depth approach highlights the dedication of the UPC and the local officials to this project. Three main approaches were set as a main policy direction and an implementation pathway:

1. To leave all existing building stock unharmed, but freeze future permits on existing empty plots, purchase these plots (or exchange them with available government plots elsewhere) and use them for the regeneration purposes.

2. To demolish a large number of buildings (after compensating the owners) in order for a more open and better-connected public space to occur.

3. To build new buildings whenever it could apply, according to available land and density (in terms of community facilities' standards).

Needless to analyze the social consequences of the second - especially pathway in a city with an already weak collective memory and at the same time the increasing costs regarding the first approach, all of them lack two vital elements in contemporary approaches of urban regeneration: the inclusion of mass transportation means and public participatory procedures. Both of them are also major points within the New Urban Agenda framework (as part of the Habitat III conference in Quito, Ecuador) and the related "Quito Papers".

There is a second initiative that runs parallel to the one described in the city's strategic framework. In absence of a reminiscent of any pre-oil specimen of architecture or urbanism (except from Qasr Al Hosn, the old Palace), the oldest buildings in town don't exceed forty years of age. Some of them were considered to be of significant value to the civic life in the 70's and the 80's, however, the construction frenzy that occurred dwarfed these buildings, both literally (due to bigger heights and volumes) and metaphorically (in terms of attention-catching). Pascal Menoret published a list of thirty one buildings and monuments that carried clear characteristics of mainly modernist and postmodernist design influences, based on the DoCoMoMo principles. ${ }^{37}$ These buildings were the only few remaining to provide some cultural background to the urban and architectural heritage of the city, to tell the tale of a fast-passing era. The epicenters of that list were the demolished central market (now replaced

37. Menoret, The Abu Dhabi guide. Modern Architecture 1950s-1990s, 2014. 
by Sir N.Foster's World Trade Center mall) and the existing Bus station in Muroor street, a subject of a wide debate in the city in terms of its demolition or preservation as a fine example of modernism. That debate was the spark that launched a case of buildings' retrofitting, called: "Modern Heritage Preservation Initiative" by the Authority of Culture and Heritage (now part of the Tourism and Culture Authority or TCA). According to this, any demolition permit (for replacing an ageing building by a more shining, effective and lucrative one) should be approved by the TCA first. If the TCA recognizes any aesthetic value on the building, retrofitting it would be the new approach, piggybacked by state-funded programs and incentives. According to Menoret ${ }^{38}$ "TCA's goal is to provide citizens with a sense of continuity in time as well as in space".

\section{The Missing Link - A Closing Proposal}

The point where both initiatives meet is the dedication to the individual building. All regeneration and retrofitting initiatives are consumed by and limited in the single building or the single plot, seen exclusively from the viewpoint of ownership.

All reports and research pilots deal with the owners of the buildings alone, neglecting the users of the buildings on an everyday basis, the rentees - mostly expatriates. ${ }^{39}$ Or they fail to look at the threshold between buildings and the public space, that interactive and highly dynamic space of the city which is affected the most, especially in dense downtown areas.

As a result, the public space is missing from all debates; residents of the buildings as well. However, this research highlights a new possibility, a novel approach, on both the regeneration initiative and the buildings' retrofitting management:

The Superblocks are the rightful urban cell of Abu Dhabi, as initiated by Makhlouf and evolved through four centuries of galloping growth. Their signature features are clearly displayed and experienced. This special characteristic of the "watermelon superblock", with the high-rise exterior series of buildings mostly associated with commercial and services uses (as the fruit's rind) and the lower-rise and lower use diversity (mostly residential) interior, consists a quite original urban pattern that needs to be acknowledged as a coherent, individual urban entity. An entity inspired by Doxiadis' modules, adapted by Makhlouf and implemented by Sheikh Zayed to serve the aspirations for a new capital city and to spatially reflect the vast oil revenues. Thus, it was the inspirational result of both a modernist exercise and a pragmatistic reality. A vision against - or as it ends up being - in synergy with a vision. And in the lack of any historical, pre-oil urban core, combined with the policy of buildings' renewal, this feature itself can be the main identifiable element of Abu Dhabi's

38. Ibid, 8 .

39. Al Rashedi, The impacts and viability of urban revitalization in the city of Abu Dhabi, 2011. 
urban history. A heritage of Modernism, at an urban scale, a cultural identity that the city could aspire to manifest.

This should be the base, the starting point of reference to any future research initiative. It could also become the flagship of the city's campaigns as an emerging global city, a beacon of time-lasting, diverse culture. A city where even its own layout and plan - apart from the buildings and the human capital - is having its own special chapter, an added value of history of urbanism. An open urban planning museum, with the city grid being the main exhibit. Combined with an enrichment in methodologies regarding urban regeneration projects, such as bottom-up participatory procedures, re-assessment of the public transportation network and a set of stronger incentives on buildings and public space retrofitting (which could be considered as a future morphology inquiry for further study), it could trigger a shift to a much more open and inclusive city, with culture rightfully becoming the missing pillar. A living heritage, expecting to be grasped upon by local authorities and citizens and lead Abu Dhabi to a much more appreciated and fundamentally holistic pathway towards its future, towards 2030 and beyond.

\section{Bibliography}

Abu Dhabi Municipality (ADM). Abu Dhabi, Dana of the Gulf. Abu Dhabi: ADM, Planning and Urban Development, Studies and Research section, 2003.

Abu Dhabi Urban Planning Council (UPC). Abu Dhabi Plan 2030, Urban Structure Framework Plan. 2007. [Accessed March 2017].

Al Fahim, Mohammed. From rags to riches; A story of Abu Dhabi. $2^{\text {nd }}$ Edition. Abu Dhabi: Makarem, 2013.

Al Rashedi, Yasmeen. The impacts and viability of urban revitalization in the city of Abu Dhabi. Master's Thesis. Abu Dhabi: Paris Sorbonne University, 2011.

Busquets, Juan. Barcelona. The urban evolution of a compact city, Rovereto: Nicolodi/Harvard University, 2005.

Doxiadis, Constantinos Apostolos. Ekistics. An Introduction to the Science of Human Settlements. New York: Oxford University Press, 1968.

Elsheshtawy, Yasser. The Evolving Arab City: Tradition, modernity \& urban development. London: Routledge, 2011.

Kanna, Ahmed. The superlative city. Dubai and the urban condition in the early twenty-first century. Cambridge MA: Harvard University Press, 2013.

Koolhaas, Rem and H. U. Obrist. Project Japan: Metabolism Talks. Taschen, 2009.

Kyriazis, Apostolos, Evgenios Balassis and Nikolaos Patsavos. "Housing in the sand and social inertia; A case study from Saudi Arabia." Presented at the Housed by choice, housed by force. In AMPS Conference Publication Series 5. Housed by Choice-Housed by Force - Homes Conflicts and Conflicting Interests. Edited by G., Artopoulos, C. Hadjichristos and G. Cairns. Nicosia: University of Cyprus; The Cyprus Institute, 2016, 80-90.

Makhlouf, Abdelrahman. Life Journey with Urbanization: Documenting the heritage of Abu Dhabi's urban development during the period from 1968 to 2014. BeirutLebanon: Arab Office for Architecture and Planning, 2015.

Menoret, Pascal. Joyriding in Riyadh. Oil, urbanism and road revolt. New York: Cambridge University Press, 2014. 
Menoret, Pascal. The Abu Dhabi guide. Modern Architecture 1950s-1990s. Abu Dhabi: Menoret Pascal, 2014.

Middleton, Deborah. Growth and Expansion in Post-War Urban Design Strategies: C. A. Doxiadis and the First Strategic Plan for Riyadh Saudi Arabia (1968-1972). PhD Thesis. Georgia Institute of Technology, 2009.

Patricios, Nicholas. "Urban design principles of the original neighbourhood concepts." Urban Morphology 1 (2002): 21-32.

Portal 9. Plans the Earth Swallows: An Interview with Abdulrahman Makhlouf. Issue 2, Spring 2013. http://portal9journal.org/articles.aspx?id=92.

Samarrai, Kais. "The evolution of Abu Dhabi City's urbanization and the sustainability challenge." In Shaping Cities; Emerging models of planning practice. Edited by M. Al-Asad and R. Mehrotra. Berlin: Hatje Cantz, 2016. 
